\title{
Peritoneal Dialysis as an Urgent-Start Option for Incident Patients on Chronic Renal Replacement Therapy: World Experience and Review of Literature
}

\author{
Dayana Bittencourt Dias ${ }^{a}$, Marcela Lara Mendes ${ }^{b} \quad$ Camila Albuquerque Alves $^{b}$ \\ Jacqueline Teixeira Caramori ${ }^{a}$ Daniela Ponce ${ }^{a, b}$

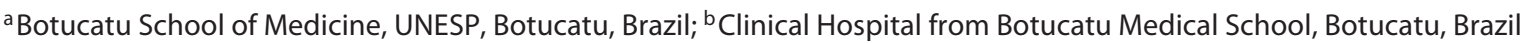

\section{Keywords}

Chronic kidney disease · Peritoneal dialysis · Hemodialysis . Urgent start · Mortality

\begin{abstract}
Chronic kidney disease is a significant problem of public health worldwide, and up to $60 \%$ of patients start dialysis in an unplanned manner without a definitive dialysis access. Recently, peritoneal dialysis (PD) has emerged as an alternative to unplanned chronic dialytic method, and the world collective experience shows that PD can be an efficient, safe, and cost-effective alternative with comparable outcomes to the planned PD and urgent-start hemodialysis (HD). More importantly, as compared to urgent-start HD using a central venous catheter, urgent-start PD has significantly fewer incidences of catheter-related bloodstream infections, dialysisrelated mechanical complications, and need for dialysis catheter reinsertions during the initial time of the therapy. An integrative review was conducted on PD urgent start compared to HD urgent start and to planned PD, identifying its potential advantages and limitations. Literature search was performed within multiple databases, and observational studies on clinical experience with urgent PD were reviewed and appraised.

(c) 2020 S. Karger AG, Basel
\end{abstract}

\section{Introduction}

Despite the biggest and best efforts of the nephrology community to start patients on dialysis in a planned manner, nearly $60 \%$ of patients initiate dialysis in an unplanned way [1]. Traditionally, hemodialysis (HD) through a central venous catheter (CVC) has been the default treatment option for almost all patients, and peritoneal dialysis $(\mathrm{PD})$ has not usually been considered a viable and safe option [2]. In the United States, in 2015, $92.8 \%$ of prevalent patients on dialysis were treated with HD [2]. Canadian registers showed that $80 \%$ of incident patients were treated with HD [3]. In Brazil, data from 2018 showed that $93.1 \%$ of patients in chronic dialysis are subjected to HD and only $6.9 \%$ to PD [3].

While PD was historically widely used in nephrology, it has been underutilized over the years due to unclear reasons, especially in patients incident in renal replacement therapy (RRT) [4]. Several reasons for the PD underutilization can be considered: the perception that it is inferior to HD because HD is associated with higher technology; the worries about infectious, mechanical, and metabolic complications associated with the PD method; the lack of experience and evidence concerning urgentstart PD, the relative ease of CVC catheter insertions and karger@karger.com

(c) 2020 S. Karger AG, Basel

www.karger.com/bpu

Karger ${ }^{\prime}=$
Daniela Ponce

Avenue Alameda das Hortências

823 Parque das Cascatas

Botucatu 18607390 (Brazil)

E-Mail daniela.ponce@ unesp.br or dponce@ fmb.unesp.br 
physicians' familiarity and comfort with the initiation of HD in urgent-start dialysis; the greater financial reimbursement of HD and the difficulties with the implant of the peritoneal catheter by the nephrologist $[2,3,5]$.

However, in the last decade, a number of reports describing the successful initiation of PD soon after the PD catheter insertion have been published making PD a viable option for urgent-start dialysis. This article examines the rationale behind this approach and reviews the current literature on the effectiveness, safety, and feasibility of urgent-start PD in developed and developing countries as compared to urgent-start HD and conventional PD.

\section{Urgent-Start Dialysis: The Concept}

In the last years, some authors have pointed out the impact of the type of vascular access utilized in the mortality of incident patients in HD [6-8]. These studies have identified that the use of CVCs is directly associated with lower survival, especially in the first 90 days of RRT. Besides that, there was major risk of bacteremia, sepsis, and hospitalizations when compared with the use of arteriovenous fistulas (AVF), arteriovenous graft, or PD catheter $[6,8]$.

Perl et al. [6] evaluated 40,526 patients between 2001 and $2008,19 \%$ initiated PD and $81 \%$ in HD. Among the HD patients, 78.6\% initiated RRT using CVC, which was an independent risk factor for death in comparison to patients which utilized the AVF method and those treated with $\mathrm{PD}$, presenting mortality, after 90 days, of, respectively, 15.6, 6.1, and 7.4\% $(p<0.05)$.

In this scenario, PD emerges as an option for unplanned start RRT in chronic kidney disease (CKD) patients stage 5 with no functioning vascular access, offering the advantage of lower use of temporary CVCs, besides the preservation of the vascular access and of the residual renal function [8-11].

By definition, urgent-start dialysis corresponds to the beginning of hemodialytic treatment without definitive vascular access (AVF), that is, through CVC or PD utilizing the catheter in $<14$ days after its implant [8-11]. Recently, the concept of urgent-start PD was revised by Blake and Jain [11], and it was considered a treatment strategy corresponding to patients with advanced but previously unknown CKD that start RRT in $\mathrm{PD}$, using the Tenckhoff catheter within $72 \mathrm{~h}$ after the implant with no previous utilization of HD therapy [11].

Despite the great efforts of the nephrology community, the majority of CKD patients begin RRT in an unplanned manner [1]. Danish Register of Nephrology per-

PD as Urgent-Start Option for Patients on

Chronic RRT: Review of Literature formed from 2008 until 2011 verified that $50 \%$ of incident patients on RRT started dialysis in an unplanned manner [8]. In Brazil, up $60 \%$ of incident patients had urgent-start RRT in 2018 [3].

Different protocols and prescriptions for urgent-start PD have been reported in the world literature. The utility of urgent-start PD is independent of the mode of PD catheter insertion. Successful urgent-start PD programs have been described with open surgical, laparoscopic, and percutaneous techniques of PD catheter insertions. Therefore, the method of PD catheter insertion is not a barrier to urgent-start PD provided the PD catheter can be inserted urgently at short notice. If clinically indicated, PD can be initiated immediately post PD catheter insertion $[9,10]$. More stable patients can be discharged after the PD catheter insertion, and urgent-start PD can be started within a few days in an outpatient regime, either at an outpatient urgent-start PD facility or in the patient's home under strict supervision [11-14].

The majority of the reported prescriptions are designed to provide intermittent PD (IPD) with low fill volumes in strict supine posture, either manually or with the help of a cycler [5, 9-12, 15-18]. Typical therapy consists of $4-5$ cycles over $8-10 \mathrm{~h}$ a day [9-11]. Depending on the patient's condition, the treatment can be provided from 3 times a week to daily [5]. The fill volumes are gradually increased during the initial 2 weeks of therapy $[5,9,10]$. However, some patients needed high-volume PD (HVPD) for achieving metabolic and fluid control [1, 18].

Recently, the interest in urgent-start PD has emerged and increased in both developing and developed countries, with several publications comparing the urgentstart PD with conventional PD and urgent-start $\mathrm{HD}$ in CKD patients $[5,10,12-21]$.

\section{PD Urgent Start in Developed Countries}

The first description of an urgent-start PD program was performed by Lobbedez et al. [19], in France, in 2008. The authors studied 60 patients that initiated unplanned dialysis (34 in PD and 26 in HD), and there were no differences between the 2 dialysis methods regarding the patients survival $(78.8 \%$ in the HD group vs. $82.9 \%$ in the PD group $(p=0.26)$.

In 2012, Koch et al. [18] evaluated for 5 years (20052010), in German, 57 incident patients in HD and 66 in PD, both with unplanned start, and showed no difference in mortality between the 2 methods. In 2013, Danish data showed similar results, but when comparing urgent-start 
PD to the planned PD program, the unplanned manner presented more mechanical complications, mainly leakage, though it did not affect the technique and patient's survival [16].

Alkatheeri et al. [15], in a Canadian university hospital, have established since July/2010 the unplanned PD program. In 3 years, 30 patients were included, and mechanical or infectious complications were evaluated (first 4 weeks after implant of the PD catheter). Dialysate leak was observed in 3 patients (10\%), it was conducted in a conservative manner; and migration of the catheter tip happened in 6 patients (20\%). Despite the premature use of the PD catheter, no infectious complications were registered [15].

Povlsen and Ivarsen [12] described the urgent-start PD program in patients over 65 years with successful results. In their publication, they reported that the insertion technique of the Tenckhoff catheter was a mini laparotomy performed by surgeon and with immediate catheter use; however, they utilized a fixed prescription for all patients and initial maximum dialysate volume of 1.2 L. Normalization of the potassium and bicarbonate levels was reached in the second session and adequate urea levels were reached after 7 days of therapy. Survival patients in 3 and 12 months were, respectively, 90 and $80 \%[12]$.

An Australian publication compared the early complications (developed in $<4$ weeks) and long-term survival of patients submitted to urgent-start PD vs. planned PD. There was difference in early dialysate leak and migration of the catheter tip, being higher in the urgent-start group (12 vs. $1 \%, p=0.047$ ). No differences were observed in infectious complications. Despite the higher frequency of mechanical complications in the urgent-start group, there was no difference in survival of the technique in 1 , 2 , or 3 years ( 68 vs. $80 \%$; 48 vs. $54 \%$, and 48 vs. $38 \%$, respectively) [16].

\section{Urgent-Start PD in Developing Countries}

In Brazil, approximately $60 \%$ of patients start dialysis in an unplanned manner, using CVC [3]. In July/2014, the dialysis unit from Clinical Hospital from Botucatu School of Medicine had no vacancies for the chronic hemodialytic treatment. Thus, PD emerged as an alternative of unplanned chronic dialytic method, with the advantage of not using CVC.

Absolute or relative contraindications to PD were considered: presence of recent abdominal surgery ( $<30$ days); multiple previous abdominal surgeries (superior to 2); presence of fibrosis or peritoneal adhesions; fungal peritonitis; severe respiratory insufficiency $(\mathrm{FiO} 2>70 \%)$; abdominal wall infections; severe hyperkalemia with electrocardiographic characteristic changes; acute pulmonary edema [17, 20-22]. All catheters have been implanted by the Nephrology team using Seldinger technique, and flexible catheters with double cuff were utilized.

After the implant of the PD catheter, patients were submitted to HVPD, using automatic and continuous method (Home Choice cycler, one session $=24 \mathrm{~h}$ ). Prescribed $\mathrm{Kt} / \mathrm{V}$ was 0.5 per $\mathrm{PD}$ session, infusion volume was $20-30 \mathrm{~mL} / \mathrm{kg}$ (average of $2 \mathrm{~L}$ ), and dwell time ranged from 30 to $50 \mathrm{~min}[20,22]$. Supine position was adopted during the sessions. After hospital discharge, patients were kept in IPD, in alternated days or daily, according to the clinical and laboratorial evaluation $[17,23,24]$.

During the IPD, training of families and/or patients was performed and, when necessary, small home adaptations to receive the therapy were done. After that, the patient was included in the program of chronic PD, with home treatment and monthly nephrologist consult $[17,23,24]$. Figure 1 shows the flowchart of the urgentstart PD program in Dialysis Unit of Brazilian Clinical Hospital.

Dias et al. [23], in Brazil, evaluated 51 patients in urgent-start PD. Mean age was $57.7 \pm 19.2$ years, diabetes was the main cause of CKD (40.6\%), and uremia was the most common indication of RRT start (54.3\%). The metabolic control was reached after 5 sessions of HVPD, and 11.5 sessions of IPD were performed at dialysis unit [23]. Mechanical complications with need for intervention occurred in $17.1 \%$ and peritonitis in $14.2 \%$. Patients and technique survival in the first 180 days were higher than $80 \%$, and the impact on the growing of chronic PD program was higher than $80 \%$ in only 360 days [24].

A Chinese study evaluated 178 patients (96 in unplanned PD and 82 in unplanned HD) and showed higher early mechanical complications (first 30 days) in the HD group (24.4 vs. $5.2 \%$; $p<0.001$ ). There was no difference in infectious complications $(2.1 \%$ in PD group and $11 \%$ in HD group; $p>0.05$ ). At multivariate analysis, urgent-start HD was an independent predictor of dialysis-associated mechanical complications in the short-term (OR 5.02 [95\% CI 1.76-14.34]; $p=0.003$ ) [25].

Another Chinese study that included 922 patients treated with urgent-start PD through manual exchanges evaluated mechanical complications in the long term. 
Fig. 1. The flowchart show the urgent-start $\mathrm{PD}$ program in dialysis unit of Brazilian clinical hospital. CKD, chronic kidney disease; PD, peritoneal dialysis; CVC, central venous catheter; HD, hemodialysis; HVPD, high-volume PD; RRT, renal replacement therapy.

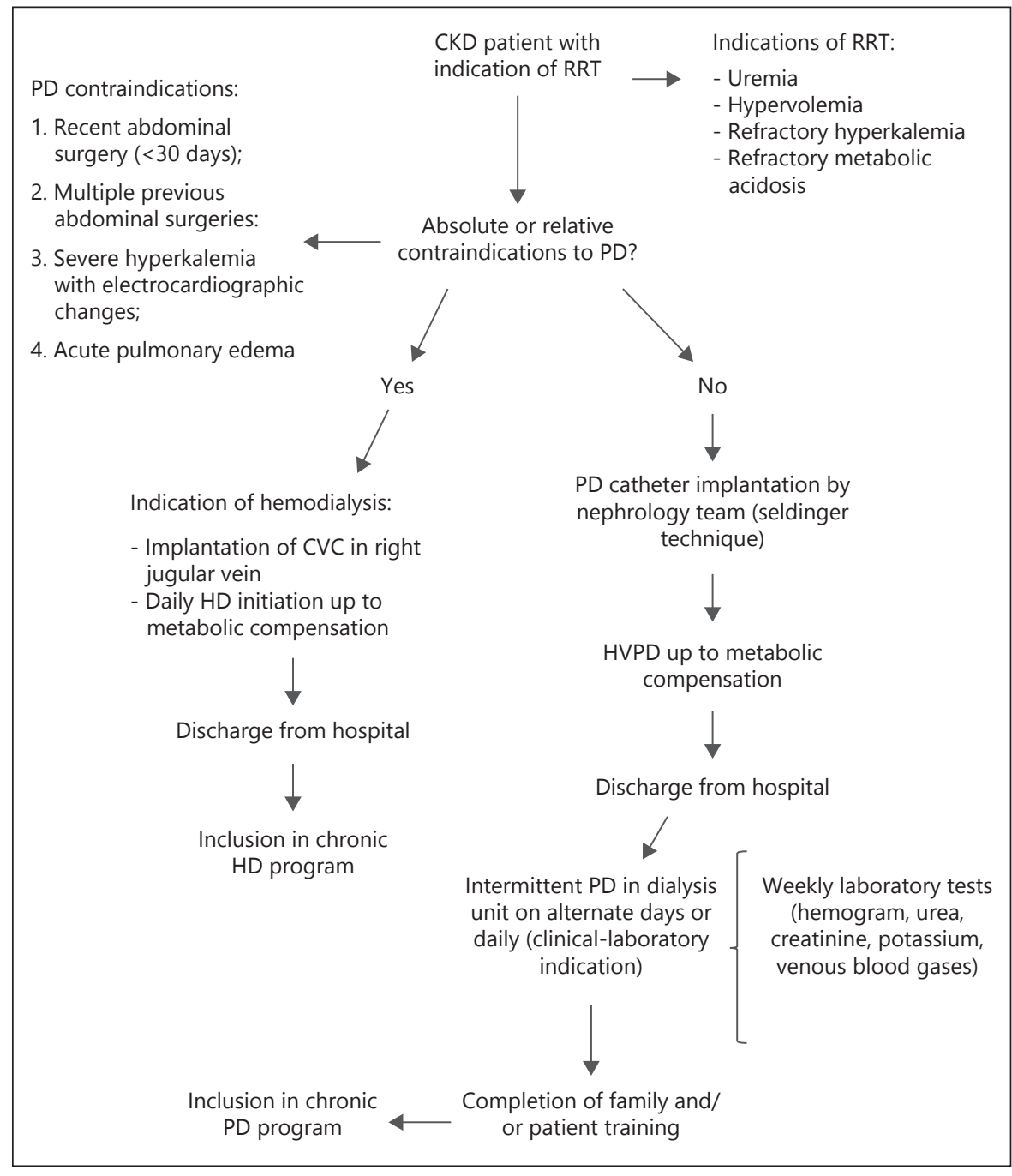

Only $4.8 \%$ of patients developed mechanical complications related to PD after follow-up time of 5.2 months: 18 inguinal hernias, 6 umbilical hernias, 11 patients with hydrothorax, and 6 with hydrocele, 2 episodes of dialysate leak to the subcutaneous and 1 case of pericatheter leak. Twenty one of the 44 patients needed to change dialysis method. Male sex and previous abdominal were independent risk factors for mechanical complications surgery (hazard ratio [HR] 5.41 [95\% CI 2.15-13.59]; $p<$ 0.001; HR 2.34 [95\% CI 1.04-5.26]; $p=0.04$ ). Evaluating 189 patients included after $2010,9.5 \%$ presented mechanical catheter dysfunction: 13 patients had fibrin obstruction, 4 patients had catheter tip migration, and 1 patient had omentum obstruction. Three of the 4 translocated catheters required surgical repositioning, and the patient with omentum obstruction was definitely transferred to HD. Higher age was a protective factor for cath- eter dysfunction (HR 0.95 [95\% CI 0.91-0.98], $p=0.005$ ) [26].

Javaid et al. [5] highlighted the importance of infrastructure and protocols in the success of the urgent-start PD program, besides the involvement of a multiprofessional team committed to the approach. In Singapore, the strategy of urgent-start PD has started in July/2015, including 17 patients. These patients were compared to 33 patients that initiated planned $\mathrm{PD}$ at the same period. Despite the urgent-start group initiating therapy with higher creatinine and urea levels, there was no difference between the 2 groups in hospitalization (7.3 vs. 7.29 episodes/patients/month, $p=0.99)$, mechanical complications ( 14 vs. $15 \%, p=1$ ), and patients survival after 180 days ( 88 vs. $94 \%, p=0.59$ ).

Table 1 summarizes the main publications of the last decade about urgent-start PD. 
Table 1. Main studies on urgent-start PD

\begin{tabular}{|c|c|c|c|c|}
\hline Authors & Year & Number of patients & Groups & Main results \\
\hline Lobbedez et al. [19] & 2008 & $\begin{array}{l}60 \\
34 \mathrm{PD} \\
26 \mathrm{HD}\end{array}$ & PD vs. HD & $\begin{array}{l}\text { No difference on survival patients after } 1 \text { year }(78.8 \\
\text { vs. } 82.9 \%, p=0.26 \text { ) survival free of re-hospitalization. } \\
\text { No difference on survival free of re-hospitalization at } \\
6 \text { months ( } 51 \text { vs. } 36 \% \text { ) and at } 1 \text { year ( } 36 \text { vs. } 21 \% \text {, } \\
p=0.12 \text { ) }\end{array}$ \\
\hline Koch et al. [18] & 2012 & $\begin{array}{l}123 \\
66 \mathrm{PD} \\
57 \mathrm{HD}\end{array}$ & PD vs. HD & $\begin{array}{l}\text { Higher rate of bacteremia in HD ( } 21.1 \text { vs. } 3.0 \% \text {, } \\
p<0.01) \\
\text { No significant difference in half-year mortality }(30.3 \\
\text { vs. } 42.1 \%, p=0.19)\end{array}$ \\
\hline Alkatheeri et al. [15] & 2016 & 30 & PD urgent-start & $\begin{array}{l}\text { No early infectious complications; } 10 \% \text { leakage ( } 3 \\
\text { patients); } 20 \% \text { cateter tip migration ( } 6 \text { patients) }\end{array}$ \\
\hline $\begin{array}{l}\text { Povlsen and } \\
\text { Ivarsen [12] }\end{array}$ & 2006 & $\begin{aligned} & 110 \\
> & 65 \text { years }\end{aligned}$ & PD urgent-start & Survival of $90 \%$ (3 months) and $80 \%$ (1 year) \\
\hline Dias et al. [17] & 2016 & 35 & PD urgent-start & $\begin{array}{l}\text { Survival of } 80 \% \text { (90 days) and growth of } 41 \% \\
\text { chronic PD }\end{array}$ \\
\hline Jin et al. [25] & 2016 & $\begin{array}{l}178 \\
96 \mathrm{PD} \\
82 \mathrm{HD}\end{array}$ & PD vs. HD & $\begin{array}{l}\text { Higher rate of general dialysis-related complications } \\
\text { in HD }(5.3 \text { vs. } 24.4 \%, p<0.001) \text {, non-infectious } \\
(3.1 \text { vs. } 13.4 \%, p=0.01) \text { and infectious complications } \\
(2.1 \text { vs. } 11 \%, p=0.01) \text { at multivariate analysis: HD } \\
\text { was risk factor for dialysis-associated mechanical } \\
\text { complications }\end{array}$ \\
\hline Xu et al. [26] & 2017 & 922 & PD urgent-start & $\begin{array}{l}\text { Only } 4.8 \% \text { of patients had mechanical complications } \\
\text { Male sex and previous abdominal surgery: risk factor } \\
\text { for mechanical dysfunction at multivariate analysis }\end{array}$ \\
\hline Dias et al. [23] & 2017 & 51 & PD urgent-start & $\begin{array}{l}\text { Patient survival in } 180 \text { days: } 82 \% / \mathrm{PD} \text { program } \\
\text { growth: } 95 \%\end{array}$ \\
\hline See et al. [16] & 2017 & $\begin{array}{l}104 \\
26 \text { urgent start } \\
78 \text { planned start }\end{array}$ & $\begin{array}{l}\text { PD urgent-start vs. } \\
\text { planned PD }\end{array}$ & $\begin{array}{l}\text { More mechanical complications in the urgent-start } \\
\text { group ( } 12 \text { vs. } 1 \%, p=0.047) \text {. No differences regarding } \\
\text { survival }\end{array}$ \\
\hline Javaid et al. [5] & 2017 & $\begin{array}{l}50 \\
17 \text { urgent start } \\
33 \text { planned start }\end{array}$ & $\begin{array}{l}\text { PD urgent-start vs. } \\
\text { planned PD }\end{array}$ & $\begin{array}{l}\text { No differences regarding hospitalization ( } 7.3 \text { vs. } 0.29 \\
\text { episodes/patients/month; } p=0.99 \text { ), mechanical } \\
\text { complications ( } 14 \text { vs. } 15 \%, p=0.99 \text { ) or survival at } 180 \\
\text { days ( } 88 \text { vs. } 94 \% ; p=0.59)\end{array}$ \\
\hline
\end{tabular}

PD, peritoneal dialysis; HD, hemodialysis.

\section{Conclusion}

PD is a safe, efficient, and cost-effective alternative to HD for patients with urgent indication of chronic dialysis, and urgent-start PD has comparable short-term outcomes to urgent-start $\mathrm{HD}$ and planned PD. In particular, as compared to urgent-start $\mathrm{HD}$, urgent-start PD has significantly fewer incidences of catheter-related bacteremia, mechanical complications, and catheter re-insertions during the initial phase of treatment. The approach of urgent-start chronic PD should be widespread in the nephrological community and offered to all patients that require RRT in urgent situations, with no contraindication of the method.

\section{Acknowledgments}

We thank nurses Laudilene Marinho and Edwa Bucuvic and doctors Pasqual Barretti and Vanessa B Banin for their contribuition. 


\section{Statement of Ethics}

We confirm that all methods were carried out are in accordance with relevant guidelines and regulations from Botucatu Medical School.

\section{Disclosure Statement}

The authors declare that there are no competing financial and nonfinancial interests.

\section{Funding Sources}

There were no funding sources.

\section{Author Contributions}

D.B.D. and M.L.M. revised the papers. D.B.D. and D.P. wrote the main manuscript text. D.P. and J.T.C. reviewed the final version of the paper.

\section{References}

1 Radhakrishnan J, Remuzzi G, Saran R, Williams DE, Rios-Burrows N, Powe N, et al.; CDC-CKD Surveillance Team; European CKD Burden Consortium; CKD.QLD group. Taming the chronic kidney disease epidemic: a global view of surveillance efforts. Kidney Int. 2014 Aug;86(2):246-50.

2 Saran R, Li Y, Robinson B, Abbott KC, Agodoa LY, Ayanian J, et al. US renal data system 2015 annual data report: epidemiology of kidney disease in the United States. Am J Kidney Dis. 2016 Mar;67(3 Suppl 1):S1-305.

3 Sood MM, Tangri N, Hiebert B, Kappel J, Dart A, Levin A, et al.; Canadian Kidney Knowledge Translation; Generation Network. Geographic and facility-level variation in the use of peritoneal dialysis in Canada: a cohort study. CMAJ Open. 2014 Mar;2(1): E36-44.

4 Brazilian Society of Nephrology [homepage on the internet]. São Paulo: Census of the Brazilian Society of Nephrology. 2017 [updated 2018 Jul 28; cited 2010 Jul 30]. Available from: www.sbn.org.br.

5 Javaid MM, Lee E, Khan BA, Subramanian S. Description of an urgent-start peritoneal dialysis program in Singapore. Perit Dial Int. 2017 Sep-Oct; 37(5):500-2.

6 Perl J, Wald R, McFarlane P, Bargman JM, Vonesh E, Na Y, et al. Hemodialysis vascular access modifies the association between dialysis modality and survival. J Am Soc Nephrol. 2011 Jun;22(6):1113-21.

7 Astor BC, Eustace JA, Powe NR, Klag MJ, Fink NE, Coresh J; CHOICE Study. Type of vascular access and survival among incident hemodialysis patients: the Choices for Healthy Outcomes in Caring for ESRD (CHOICE) Study. J Am Soc Nephrol. 2005 May;16(5):1449-55.
8 Danish Nephrology Registry. Annual Report 2011. [2 July 2019, date last accessed]. Available from: www.nephrology.dk.

9 Jo YI, Shin SK, Lee JH, Song JO, Park JH. Immediate initiation of CAPD following percutaneous catheter placement without break-in procedure. Perit Dial Int. 2007 Mar-Apr; 27(2):179-83

10 Ghaffari A. Urgent-start peritoneal dialysis: a quality improvement report. Am J Kidney Dis. 2012 Mar;59(3):400-8.

11 Blake PG, Jain AK. Urgent Start Peritoneal Dialysis: Defining What It Is and Why It Matters. Clin J Am Soc Nephrol. 2018 Aug;13(8): 1278-9.

12 Povlsen JV, Ivarsen P. How to start the late referred ESRD patient urgently on chronic APD. Nephrol Dial Transplant. 2006 Jul;21 Suppl 2:ii56-9.

13 Pai MF, Yang JY, Chen HY, Hsu SP, Chiu YL, $\mathrm{Wu} \mathrm{HY}$, et al. Comparing long-term outcomes between early and delayed initiation of peritoneal dialysis following catheter implantation. Ren Fail. 2016 Jul;38(6):875-81.

14 Liu Y, Zhang L, Lin A, Ni Z, Qian J, Fang W. Impact of break-in period on the short-term outcomes of patients started on peritoneal dialysis. Perit Dial Int. 2014 Jan-Feb;34(1):49-56.

15 Alkatheeri AM, Blake PG, Gray D, Jain AK. Success of urgent-start peritoneal dialysis in a large canadian renal program. Perit Dial Int. 2016 Mar-Apr;36(2):171-6.

16 See EJ, Cho Y, Hawley CM, Jaffrey LR, Johnson DW. Early and late patient outcomes in urgent-start peritoneal dialysis. Perit Dial Int. 2017 Jul-Aug;37(4):414-9.

17 Dias DB, Banin V, Mendes ML, Barretti P, Ponce D. Peritoneal dialysis can be an option for unplanned chronic dialysis: initial results from a developing country. Int Urol Nephrol. 2016 Jun;48(6):901-6.
18 Koch M, Kohnle M, Trapp R, Haastert B, Rump LC, Aker S. Comparable outcome of acute unplanned peritoneal dialysis and haemodialysis. Nephrol Dial Transplant. 2012 Jan;27(1):375-80.

19 Lobbedez T, Lecouf A, Ficheux M, Henri P, Hurault de Ligny B, Ryckelynck JP. Is rapid initiation of peritoneal dialysis feasible in unplanned dialysis patients? A single-centre experience. Nephrol Dial Transplant. 2008 Oct; 23(10):3290-4.

20 Ponce D, Dias DB, Balbi A. Urgent start Peritoneal Dialysis: a viable option for acute and chronic kidney failure. EMJ. 2016;1(2):26-33.

21 Gabriel DP, Nascimento GV, Caramori JT, Martim LC, Barretti P, Balbi AL. Peritoneal dialysis in acute renal failure. Ren Fail. 2006; 28(6):451-6.

22 Gabriel DP, Nascimento GV, Caramori JT, Martim LC, Barretti P, Balbi AL. High volume peritoneal dialysis for acute renal failure. Perit Dial Int. 2007 May-Jun;27(3):277-82.

23 Bitencourt Dias D, Mendes ML, Burgugi Banin V, Barretti P, Ponce D. Urgent-Start Peritoneal Dialysis: The First Year of Brazilian Experience. Blood Purif. 2017;44(4):283-

24 Dias DB, Banin V, Mendes ML, Barretti P, Ponce D. Peritoneal Dialysis as an option for unplanned initiation of chronic dialysis. Hemodial Int. 2016 Oct;20(4):631-3.

25 Jin H, Fang W, Zhu M, Yu Z, Fang Y, Yan H, et al. Urgent-Start Peritoneal Dialysis and Hemodialysis in ESRD Patients: complications and Outcomes. PLoS One. 2016 Nov;11(11): e0166181.

$26 \mathrm{Xu}$ D, Liu T, Dong J. Urgent-start peritoneal dialysis complications: prevalence and risk factors. Am J Kidney Dis. 2017 Jul;70(1):10210. 